\title{
O Efeito Clientela no Mercado Brasileiro: Será que os Investidores São Irracionais?*
}

\author{
Jairo Laser Procianoy**
}

Rodrigo dos Santos Verdi***

\section{Resumo}

Este estudo testa a existência do efeito clientela no cenário brasileiro durante os anos de 1989 a 1993, quando os impostos sobre dividendos eram zero e sobre ganhos de capital eram no máximo 25\%. Dos 693 eventos analisados, $47 \%$ dos eventos apresentaram o preço da ação no primeiro dia ex-dividend maior do que na data em que a ação tinha direito de receber dividendos. Essas constatações contrariam as expectativas do modelo e esse comportamento pode ser considerado irracional já que os investidores estariam pagando mais por uma ação sem direito a dividendos, do que quando esta tinha direito a recebê-lo. Evidencia-se um retorno anormal médio positivo no primeiro dia ex-dividend de 1,4\% para a amostra total, significativos a $0,1 \%$. Verifica-se, contra as expectativas, que a diferença de preço não diminui com o passar dos anos. As instituições financeiras possuem retornos positivos menores que as demais empresas. As ações pagadoras de maior dividend yield tiveram maiores retornos. Ao testarmos uma janela de cinco dias após o pagamento dos dividendos verificamos que os preços das ações encontraram um novo patamar de preços na data ex-dividend mas tendem a retornar ao preço inicial.

Palavras chave: Dividendos, Impostos, Efeito Clientela, Brasil.

JEL Code: G35.

\footnotetext{
* Os autores agradecem os comentários acontecidos quando da apresentação no $2^{\underline{Q}}$ Encontro Brasileiro de Finanças em 2002, Rio de Janeiro e a Ricardo Heineberg pelo auxílio na coleta de dados. A responsabilidade é total dos autores.

**PPGA/EA/UFRGS \& LVBS - Av. Carlos Gomes 1111 apto 1201 - 90.480-004 - Porto Alegre - RS - Brasil - jlprocianoy@lvbs.edu.br

***PPGA/EA/UFRGS e The Wharton School: rverdi@wharton.upenn.edu
}

$\underline{\text { Revista Brasileira de Finanças v. 1, } \mathrm{n}^{\underline{0}} \text { 2, pp.217-242 Dezembro } 2003}$ 


\begin{abstract}
This work tests the dividend clientele effect in the Brazilian stock market between 1989 and 1993, a period during which there were no dividends taxes and capital gains taxes varied between zero and $25 \%$ according to shareholders group. From a sample of 693 events studied, 47\% showed first ex-dividend day stock price higher than in the previous day. These findings were against theoretical predictions and investors' attitudes may be considered irrational because they were paying more for ex-dividend shares than for cum-dividend ones. Sample segmentation by year showed no difference. Financial institutions and first group stock yield had lower abnormal returns than others. Positive abnormal returns of $1,4 \%$ in the first ex-dividend day was found, $0,1 \%$ significant. Five days abnormal returns following last cum-dividends day study showed that stock prices increased and returned to the original price few days later.
\end{abstract}

\title{
1. Introdução.
}

A política de dividendos compreende, por parte dos gestores empresariais, a decisão de pagar dividendos aos acionistas ou reter os lucros gerados internamente no período. Trata-se de uma das decisões mais importantes do trabalho gerencial e deve buscar a maximização da riqueza do investidor.

Dentre as teorias que buscam explicar a política de distribuição de dividendos, pode-se dizer que ainda não houve consenso sobre a sua importância na valorização da firma (Black (1976) e Allen e Michaely (2002)). Alguns estudos defendem um alto índice de distribuição de dividendos, pois acreditam que esta seria uma maneira de reduzir o fluxo de caixa disponível da empresa (agência, Easterbrook, (1984) e Jensen (1986)) e de uma expectativa da existência de lucros futuros (sinalização, Allen e Michaely (2002)). Outros acreditam que a política de dividendos é irrelevante para os investidores. Miller e Modigliani (1961) afirmam que, na ausência de impostos e custos de transação, a política de dividendos não tem nenhum efeito sobre o preço das ações. O terceiro grupo argumenta 
que, em países onde os dividendos são altamente tributados, quando comparados aos ganhos de capital, este pagamento representa uma perda real para os investidores e, portanto, deve ser evitado (Ross, Westerfield e Jaffe, (1999)). O quarto grupo coloca a política de dividendos como uma decisão residual após a realização dos investimentos que maximizariam a riqueza dos acionistas (Donaldson (1961)).

O maior argumento contra o pagamento de dividendos é que, na maioria dos países estudados, os dividendos são tributados com uma alíquota superior aos ganhos de capital. Assim, seria mais adequado para o investidor vender parte de suas ações para gerar fundos, fabricando o seu próprio dividendo. Nesse caso, muitos gestores poderiam optar por distribuir seus lucros através da recompra de ações, o que seria mais interessante para os acionistas do ponto de vista tributário, dada a alta tributação sobre dividendos auferidos (Miller e Scholes, (1978)).

$\mathrm{Na}$ medida em que os investidores podem ser tributados com alíquotas de impostos diferentes, em função de suas alíquotas individuais, surge a hipótese do "Efeito Clientela", em que investidores que pagam altos impostos sobre dividendos teriam interesse em adquirir ações com um yield reduzido. Por outro lado, investidores que são tributados a uma baixa alíquota de imposto sobre dividendos teriam interesse em adquirir ações com um yield elevado (Miller e Modigliani, (1961)).

Elton e Gruber (1970) estudaram e testaram a existência do efeito clientela no mercado norte-americano e recomendam que, na ausência de impostos, o mercado deve avaliar as ações, entre outras coisas, com base no valor dos dividendos pagos. A variação no preço das ações entre o último dia em que o papel é negociado com direito a dividendos e o $1^{\underline{O}}$ dia ex-dividend deve ser igual ao valor recebido pelo portador da ação. Dessa forma, 
a variação no preço da ação deveria corresponder ao valor do dividendo descontado o valor dos impostos.

Os autores verificaram que a diferença no preço da ação com e sem direito a dividendos foi menor do que o dividendo pago. Essa constatação sinalizou que, uma vez que existem investidores com tributação distintas para as receitas oriundas de dividendos, o mercado considera essa informação para avaliar o preço da ação, fortalecendo a teoria de efeito clientela. Essas constatações foram empiricamente testadas em diversos cenários $^{1}$ e as conclusões ratificam as evidências de Elton e Gruber.

No Brasil durante os anos de 1989 a 1993, ao contrário de muitos países, os dividendos não estavam sujeitos a tributação, enquanto que os ganhos de capital sofreram incidência de impostos a uma alíquota de $25 \%$ para todos os investidores menos os fundos de pensão que eram tratados em caráter especial e não estavam sujeitos a tributação ${ }^{2}$. Além disso, todos os dividendos pagos são previamente conhecidos do mercado, uma vez que são anunciados com antecedência, o que exclui o fator informativo dos testes deste trabalho. Esse cenário permite a realização de testes que avaliem a influência dos impostos sobre dividendos nos preços das ações, num cenário tributário atípico e efetivamente testar a existência do efeito clientela no mercado acionário brasileiro.

Os resultados apresentaram uma imperfeição no mercado brasileiro ao ajustar o valor das ações na data ex-dividend. Dos

\footnotetext{
${ }^{1}$ Ver Michaely e Murgia (1995) para Itália, Amihud e Murgia (1997) para Alemanha, Frank e Jagannathan (1998) para Hong Kong, Romon (200) para França, Milonas e Travlos (2001) para Grécia, e Hayashi e Jagannathan (1990), Kato e Loewenstein (1995) para Japão e Lasfer e Zenomos (2003) para o mercado Europeu.

${ }^{2}$ Ver Neto e Saito (2003) como referência da evolução da tributação sobre dividendos na década de 90 e Procianoy e Verdi (2003) para uma análise do efeito clientela mais recente.
} 
693 eventos analisados, 47\% apresentaram o preço da ação no primeiro dia ex-dividend maior do que na data em que a ação tinha direito de receber dividendos e apenas em $5 \%$ dos casos situou-se dentro do intervalo teórico esperado. Esses resultados abrem possibilidade de que o investidor realize arbitragem comprando ações na data zero e vendendo na data 1. Evidencia-se, ainda, um retorno anormal médio positivo no primeiro dia $e x$ dividend de 1,4\% para a amostra total, significativos a $0,1 \%$. Verifica-se, ainda, uma relação diretamente proporcional entre o yield da ação e os resultados anormais encontrados ${ }^{3}$.

A próxima seção apresenta a metodologia utilizada. A Seção 3 descreve seleção e características da amostra. Os resultados são apresentados na Seção 4 e a última parte sintetiza as conclusões do estudo.

\section{Metodologia.}

Este trabalho está dividido em duas etapas. A primeira parte avalia o comportamento das ações que pagaram dividendos com base no modelo de Elton e Gruber (1970). A segunda verifica a existência de retornos anormais num período de 11 dias em torno da data em que as ações foram negociadas com direito a receber dividendo.

Elton e Gruber (1970) testaram a variação do preço da ação no primeiro dia de negociação do título sem direito ao dividendo anunciado. Segundo os autores, o preço teórico da ação na data ex-dividend seria:

$$
P_{1}=P_{0}-D^{*}\left(\frac{1-I_{d i v}}{1-I_{G c a p}}\right)
$$

\footnotetext{
${ }^{3}$ Resultados semelhantes foram encontrados por Verdi (2001) analisando o mercado brasileiro durante os anos de 1996 a 1998.
} 
onde, $P_{0}$ seria o preço da ação no último dia com direito a dividendos; $P_{1}$, o preço da ação no primeiro dia ex-dividend; $D$, o valor do dividendo pago por ação; $I_{d i v}$, a alíquota de impostos incidentes sobre os dividendos; e $I_{G c a p}$, a alíquota de impostos incidentes sobre os ganhos de capital.

Para esse trabalho, em que não há incidência de impostos sobre dividendos no período estudado e os ganhos de capital são tributados nas alíquotas de $0 \%$ e 25\%, em função do tipo de investidor, o preço da ação pagadora de dividendos em seu primeiro dia de negociação ex-dividend deveria variar entre os extremos de impostos denominados de preço teórico mínimo $\left(P_{1 T \text { mín }}\right)$ e preço teórico máximo $\left(P_{1 T \text { máx }}\right)$.

Supondo que alíquota de impostos sobre os ganhos de capital fosse igual a $25 \%$ (o investidor seria pessoa física ou jurídica), o valor mínimo teórico para $P_{1}$ seria:

$$
P_{1 T \text { mín }}=P_{0}-D / 0,75
$$

Caso a alíquota de impostos sobre os ganhos de capital fosse igual a zero (o investidor seria um fundo de pensão), o valor da ação teórico máximo esperado seria:

$$
P_{1 T \text { máx }}=P_{0}-D
$$

O preço da ação $P_{1}$, para o primeiro dia ex-dividend, deveria situar-se dentro do intervalo abaixo:

$$
P_{1 T \text { mín }} \leq P_{1} \leq P_{1 T \text { máx }}
$$

Além disso, como instrumento metodológico criamos a variável $D P_{1}$ que é a relação entre o preço efetivo da ação na data "1", primeiro dia ex-dividend, e o valor teórico mínimo esperado desta ação para esse dia $\left(P_{1 T \text { mín }}\right)$ A variável $D P_{2}$ representa a relação do preço da ação com o valor teórico 
máximo $\left(P_{1 T \text { máx }}\right)$. Estas variáveis foram calculadas segundo as equações 5 e 6 a seguir:

$$
\begin{aligned}
& D P_{1}=\left(\frac{P_{1}}{P_{1 T \text { mín }}}\right)-1 \\
& D P_{2}=\left(\frac{P_{1}}{P_{1 T \text { máx }}}\right)-1
\end{aligned}
$$

\subsection{Ajuste das Diferenças de preço ao Mercado.}

O preço da ação na data 1 pode ser influenciado por um movimento do mercado, assim é necessário que este valor seja ajustado ao mercado, evitando um viés no modelo. O preço da ação na data "1" foi ajustado com base no critério abaixo:

$$
P_{1 a}=K * P_{1}
$$

onde $P_{1 a}$ é o valor na ação no primeiro dia ex-dividend ajustado ao mercado; $P_{1}$ é o preço da ação na data " 1 " e $K$ é um coeficiente de ajuste ao mercado:

$$
K=1 /\left(\operatorname{Ibov}_{1} / \operatorname{Ibov}_{0}\right)
$$

$I b o v_{0}$ e $I b o v_{1}$ são os valores do índice Ibovespa nas datas 0 e 1 respectivamente. Nesse caso, as diferenças de preço na data "1" ( $D P_{1}$ e $\left.D P_{2}\right)$ foram ajustadas alterando o valor de $P_{1}$ para $P_{1 a}$.

\subsection{Cálculo dos Retornos Anormais para a Janela do Evento.}

A metodologia de estudos de eventos permite verificar a existência de retornos inesperados associados a um evento, 
centrando-se na anormalidade do retorno das ações em torno ou na data do mesmo (Brown e Warner (1980 e 1985)). Esse método permite verificar a existência de retornos inesperados associados a um evento, centrando-se no retorno das ações em torno da data do evento.

Brown e Warner (1980, 1985) sugerem três modelos que podem ser utilizados para calcular os retornos anormais em estudos de eventos. Esses modelos são: o modelo de retornos ajustados à média, o modelo de retornos ajustados ao mercado e o modelo de retornos ajustados ao risco e ao mercado. KLOECKNER (1992) verificou que os três modelos anteriores estimam os retornos anormais de forma consistente e similar. Dessa forma, optou-se por calcular os retornos anormais segundo o modelo de retornos ajustados ao mercado (equações 9 e 10) e avaliou-se a existência de retornos anormais das ações estudadas em uma janela de evento de 11 dias com o ponto médio no último dia com dividendos.

$$
R_{i t}=\log \left(P i_{t}\right)-\log \left(P i_{t-1}\right)
$$

sendo $R_{i t}$ o retorno da ao $i$ na data $t$ e $P i_{t}$, o preço da ação $i$ na data $t^{4}$.

$$
A R_{i t}=R_{i t}-R_{m t}
$$

$A R_{i t}$ é o retorno anormal da ação $i$ na data $t ; R_{i t}$ é o retorno da ação na data $t$; e $R_{m t}$, o retorno do portifólio de mercado na data $t$. Nesse trabalho utiliza-se o retorno do Índice da Bolsa de Valores de São Paulo - IBOVESPA.

Além disso, os retornos anormais médios devem ser agregados em uma seqüência cronológica de modo que quantifiquem

\footnotetext{
${ }^{4}$ No cálculo do retorno da ação na data 1 utilizou-se o preço da ação na data 1 somado ao valor do dividendo pago.
} 
a variação anormal ao longo do tempo, definindo, então, um retorno anormal cumulativo no período em estudo (MacKinlay, 1997).

$$
C A R_{t}=\left(\left(1+C A R_{t-1}\right) *\left(1+\overline{A R_{t}}\right)\right)-1
$$

$C A R_{t}$ é o retorno anormal cumulativo da ação entre a data "0" e a data "t"; $\overline{A R_{t}}$, o retorno anormal médio no instante $t$.

\section{Descrição da Amostra.}

Este estudo foi constituído de empresas cujas ações foram negociadas na Bolsa de Valores de São Paulo entre as datas de $1^{\mathrm{O}}$ de janeiro de 1989 e 31 de dezembro de 1993 e que pagaram pelo menos um dividendo a seus acionistas durante esse período $^{5}$.

A população alvo deste trabalho foi 1569 distribuições de dividendos. Deste grupo, excluiu-se os casos em que as ações não foram negociadas nas datas cum-dividend e ex-dividend, resultando em uma amostra total de 693 eventos, de 132 empresas. Os dados foram selecionados do banco de dados Economática. Para as cotações, utilizou-se o valor médio da ação no dia de negociação ${ }^{6}$.

Em relação ao yield encontrado, é importante ressaltar que metade dos eventos apresentavam yield inferior a 1,2\% (mediana) apesar do valor do yield médio encontrado ter sido de

\footnotetext{
${ }^{5}$ Apesar do período estudado ter sido caracterizado por altos níveis de inflação, resultados semelhantes foram encontrados em períodos sem hiperinflação depois do Plano Real de 1994, como por exemplo em Verdi (2001) e Procianoy e Verdi (2003).

${ }^{6}$ Optamos por utilizar cotaçõoes médias pois, na nossa opinião, refletem melhor o ganho médio de um investidor que negociasse as ações nas datas 0 e 1. Além disso, se optássemos por cotações de fechamento, existiria a eventualidade de variações pequenas resultarem de eventuais manipulações no mercado como resultado do preço objetivo de fechamento para algum investidor.
} 
2,8\%. Mais de $80 \%$ dos eventos apresentaram yield inferior a $5 \%$, o que caracteriza a amostra por um yield reduzido ${ }^{7,8}$. Isso significa que a amostra caracteriza-se por um baixo pagamento de dividendos em relação ao preço das ações no contexto geral. A Tabela 1 expõe a distribuição dos yields encontrados em valores percentuais:

Tabela 1 - Distribuição da Amostra por Níveis de Yield.

\begin{tabular}{lccccc}
\hline \hline Yield(\%) & 0 a 1 & 1 a 2 & 2 a 5 & 5 a 10 & 10 a 100 \\
\hline Eventos & 313 & 128 & 128 & 85 & 39 \\
$\%$ & $45,17 \%$ & $18,47 \%$ & $18,47 \%$ & $12,27 \%$ & $5,63 \%$ \\
\hline
\end{tabular}

Analisando a representatividade da amostra em relação as ações negociadas no mercado brasileiro, comparou-se as empresas dos eventos selecionados com as que compunham o IBOVESPA no período médio estudado (maio a agosto de 1991). O índice era composto por 57 papéis. Nesse estudo, utilizou-se dados que representavam $65 \%$ das empresas do índice e $97,8 \%$ da sua participação teórica. Isso indica que foram tomadas ações de alta liquidez no mercado acionário brasileiro.

Da amostra total, verificou-se a existência de 31 setores distintos. A distribuição setorial dos 693 eventos apresentou uma predominância das instituições financeiras com 273 casos (39,4\% da amostra total), e do setor industrial com 101 eventos (14,7\% da amostra), sendo 31 eventos das indústrias siderúrgicas e 70 casos dos outros ramos industriais.

\footnotetext{
${ }^{7}$ Para uma comparação dos yields das ações ver Ramos (1997), onde é encontrado valores de yields superiores para o período de 1988 a 1993.

${ }^{8}$ Vale ressaltar que um yield reduzido, não significa um dividendo reduzido, mas sim, que a relação dividendo versus preço era reduzida. Isso significa que, mesmo que as empresas brasileiras paguem pelo menos $25 \%$ do lucro líquido ajustado, ainda assim, num mercado sobrevalorizado, o yield poderá ser pequeno.
} 
Quanto à freqüência da distribuição de dividendos por uma mesma empresa, temos que das 151 ações distribuídas em 132 empresas distintas que compunham a amostra total, apenas 22 ações de 17 empresas distribuíram dividendos nos cinco anos em estudos, resultando em 358 eventos. Além disso, apenas 11 ações de 8 empresas pagaram dividendos pelo menos duas vezes em cada um dos cinco anos pesquisados. Isso representa que apenas alguns papéis são freqüentemente pagadores de dividendos. A Tabela 2 apresenta um resumo da amostra em relação a freqüência de pagamentos de dividendos anuais.

Tabela 2 - Empresas que Pagaram Dividendos

Uma ou Mais Vezes por Ano

\begin{tabular}{lccc}
\hline \hline Dividendo & Eventos & Empresas & Ações \\
\hline $1 \times$ ou + em 5 anos & 693 & 132 & 151 \\
$1 \times$ por ano & 358 & 17 & 22 \\
$2 \times$ ou + por ano & 272 & 8 & 11 \\
\hline
\end{tabular}

Outra constatação é que das oito empresas que pagaram dividendos duas vezes ou mais em cada ano, quatro eram provenientes do setor financeiro, isto é, essas instituições foram mais constantes no pagamento de dividendos.

\section{Análise dos Resultados.}

\subsection{Amostra Total.}

Nessa seção são determinadas as diferenças de preço mínimas e máximas $\left(D P_{1}\right.$ e $\left.D P_{2}\right)$ para a amostra total antes e após o ajuste ao mercado (Tabela 3 ). Os resultados encontrados apresentaram um valor médio de $D P_{1}$ de $4,25 \%$ antes do ajuste ao mercado significativo a $0,1 \%$. Após o ajuste, a diferença de preço encontrada foi de 3,23\% com nível de significância de $0,1 \%$. Além disso, o preço das ações na data ex-dividend 
situou-se 1,98\% acima do valor máximo estabelecido por Elton e Gruber $\left(D P_{2 a}\right)$. Isso demonstra que, para a amostra total, o comportamento do preço das ações não se ajustou conforme as expectativas teóricas e, na maioria dos casos ( $58 \%$ dos eventos), foi maior do que o valor projetado.

Tabela 3 - Diferenças de Preço $\left(D P_{1}\right.$ e $\left.D P_{2}\right)$ para a Amostra Total Antes e Após o ajuste ao mercado

\begin{tabular}{lcccc}
\hline \hline Estat.Descritiva & $D P_{1}$ & $D P_{1 a}$ & $D P_{2}$ & $D P_{2 a}$ \\
\hline Média & $0,0425^{*}$ & $0,0323^{*}$ & $0,0298^{*}$ & $0,0198^{*}$ \\
Desvio Padrão & 0,1137 & 0,1094 & 0,0836 & 0,0810 \\
Mediana & 0,0224 & 0,0154 & 0,0163 & 0,0083 \\
Maior Valor & 1,6313 & 1,5477 & 0,9253 & 0,8641 \\
Menor Valor & $-0,2888$ & $-0,2991$ & $-0,2947$ & $-0,3049$ \\
Eventos & 693 & 693 & 693 & 693 \\
Teste T & 9,85 & 7,77 & 9,39 & 6,42 \\
\hline
\end{tabular}

*: Nível de significância de $0,1 \%$.

Para maior confiabilidade dos resultados, nos cálculos seguintes será utilizada a amostra ajustada ao mercado e será trabalhado com a amostra total excluída dos outliers. A retirada dos outliers se faz necessária como forma de obter uma amostra mais homogênea e a redução da possibilidade de que as médias sejam afetadas por valores extremos.

\subsection{Tratamento de Outliers.}

A exclusão dos outliers, valores que se distanciam da média em dois desvios padrões para mais ou para menos, resultou em uma sub-amostra com 686 eventos. Dos sete eventos excluídos, todos apresentaram valores positivos em relação à média, ou seja, caso a amostra completa fosse influenciada pelos outliers o seria para resultados mais positivos. 
A Tabela 4 apresenta os resultados da amostra ajustada ao mercado antes e após a exclusão dos outliers. A amostra sem outliers apresentou uma diferença média de preço na data "1" $\left(D P_{1 a}\right)$ de $2,48 \%$, um pouco inferior aos valores da amostra total $(3,23 \%$ ), ambos significativos a $0,1 \%$ (teste $t$ subiu de 7,77 para 9,37$)$. A diferença de preço $D P_{2 a}$ encontrada foi de $1,48 \%$ e também significativo a $0,1 \%$. O teste $Z$ de diferença das médias não apresentou valores significativos ( $Z$ igual a 1,52), mostrando que as médias não são distintas estatisticamente.

Dos 686 eventos, em apenas 5\% dos casos, o valor da ação na data 1 situou-se dentro do intervalo teórico esperado (entre $P_{1 T \text { mín }}$ e $\left.P_{1 T \text { máx }}\right)$. Em 400 casos ( $58 \%$ dos eventos) o preço da ação foi maior do que $P_{1 T \text { máx }}$ e em 254 casos (37\% dos eventos) o preço da ação ficou abaixo de $P_{1 T \text { mín }}$. Outra constatação importante é que em $47 \%$ dos eventos, o valor médio de $P_{1}$ encontrado foi superior ao valor médio de $P_{0}$, isto é, o valor da ação subiu no primeiro dia em que foi negociado sem direito a dividendos. Nestes casos os investidores estariam pagando por uma ação sem direito a dividendos um valor maior do que foi pago quando a ação tinha direito a recebê-los.

Tabela 4 - Diferenças de Preço $\left(D P_{1 a}\right.$ e $\left.D P_{2 a}\right)$ para

Amostra Ajustada ao Mercado com e sem Outliers

\begin{tabular}{llllc}
\hline \hline & \multicolumn{2}{c}{ Amostra total } & \multicolumn{2}{c}{ Amostra S/outliers } \\
Estat. Descritiva & $D P_{1 a}$ & $D P_{2 a}$ & $D P_{1 a}$ & $D P_{2 a}$ \\
Média & $0,0323^{*}$ & $0,0198^{*}$ & $0,0248^{*}$ & $0,0148^{*}$ \\
Desvio Padrão & 0,1094 & 0,0810 & 0,0693 & 0,0615 \\
Mediana & 0,0154 & 0,0083 & 0,0147 & 0,0074 \\
Maior Valor & 1,5477 & 0,8641 & 0,3903 & 0,2872 \\
Menor Valor & $-0,2991$ & $-0,3049$ & $-0,2991$ & $-0,3049$ \\
Eventos & 693 & 693 & 686 & 686 \\
Teste T & 7,77 & 6,42 & 9,37 & 6,28 \\
Teste Z & 1,52 & 1,29 & & \\
\hline
\end{tabular}

*: Nível de significância de $0,1 \%$. 
O principal impacto da exclusão dos outliers é que tornou a amostra mais confiável para aplicação dos testes futuros.

\subsection{Segmentação da Amostra.}

A amostra foi segmentada para verificar a existência de algumas evidências mais específicas que explicassem o comportamento anormal evidenciado. Os critérios de segmentação foram: o ano de pagamento do dividendo (1989, 1990, 1991, 1992 e 1993), a classe da ação (ordinária ou preferencial), o setor da empresa (instituições financeiras e demais setores) e o yield da ação.

\subsubsection{Ano de Pagamento.}

A comparação entre anos verifica se existe algum comportamento específico nos anos em estudo que explique algum fator comum entre os eventos, externo a empresa e ao mercado de capitais, micro ou macroeconômico, que tenha interferido no resultado encontrado.

A Tabela 5 apresenta os valores de $D P_{1 a}$ e $D P_{2 a}$ para cada ano estudado. As diferenças de preços encontradas foram semelhantes entre os anos com exceção no ano de 1992, em que a diferença de preço foi significativamente menor que nos anos restantes ( $0,8 \%$ comparado a 2,5\% em média). O teste de diferença de médias (Tabela 6) apresentou significância estatística $(0,1,1$ e 5\%) apenas quando comparou-se o ano de 1992. Nas comparações restantes, os valores de $Z$ não foram significantes. Isso demonstra que não houve diferença na formação de preços nas datas ex-dividend. A expectativa era que, com o passar do tempo, a diferença no preço da ação na data "1" diminuísse em função do conhecimento desta anormalidade e da possível obtenção de ganhos extraordinários por agentes deste 
mercado em processos de arbitragem entre as datas " 0 " e "1", porém isso não ocorreu.

Tabela 5 - Comparação entre Anos

\begin{tabular}{lccccc}
\hline \hline$D P_{1 a}$ & 89 & 90 & 91 & 92 & 93 \\
\hline Média & $0,0259^{*}$ & $0,0376^{*}$ & $0,0237^{*}$ & 0,0080 & $0,0246^{*}$ \\
Desvio Padrão & 0,0735 & 0,0836 & 0,0721 & 0,0559 & 0,0488 \\
Mediana & 0,0175 & 0,0243 & 0,0096 & 0,0016 & 0,0208 \\
Maior Valor & 0,3040 & 0,3903 & 0,2818 & 0,2030 & 0,2123 \\
Menor Valor & $-0,2991$ & $-0,1275$ & $-0,1372$ & $-0,1901$ & $-0,1035$ \\
Eventos & 186 & 142 & 115 & 112 & 131 \\
Teste T & 4,81 & 5,35 & 3,527 & 1,52 & 5,77 \\
\hline DP2a & 89 & 90 & 91 & 92 & 93 \\
\hline Média & $0,0154^{*}$ & $0,0222^{*}$ & $0,0137^{* * *}$ & 0,0024 & $0,0174^{*}$ \\
Desvio Padrão & 0,0672 & 0,0698 & 0,0651 & 0,0510 & 0,0458 \\
Mediana & 0,0094 & 0,0119 & 0,0045 & $-0,0044$ & 0,0125 \\
Maior Valor & 0,2872 & 0,2682 & 0,2654 & 0,1601 & 0,1472 \\
Menor Valor & $-0,3049$ & $-0,1315$ & $-0,1523$ & $-0,1929$ & $-0,1183$ \\
Eventos & 186 & 142 & 115 & 112 & 131 \\
Teste T & 3,12 & 3,79 & 2,25 & 0,50 & 4,34 \\
\hline
\end{tabular}

*,***: Nível de significância de 0,1 e $5 \%$ respectivamente.

Tabela 6 - Diferença de Médias entre Anos

\begin{tabular}{lrrrrc}
\hline \hline$D P_{1 a}$ & 89 & 90 & 91 & 92 & 93 \\
89 & 0,00 & 1,31 & 0,26 & $2,37^{* *}$ & 0,19 \\
90 & & 0,00 & 1,43 & $3,36^{*}$ & 1,58 \\
91 & & 0,00 & $1,83^{* *}$ & 0,12 \\
92 & & & 0,00 & $2,44^{* *}$ \\
93 & & & & 0,00 \\
\hline$D P_{2 a}$ & 89 & 90 & 91 & 92 & 93 \\
89 & 0,00 & 0,90 & 0,22 & $1,88^{* * *}$ & 0,32 \\
90 & & 0,00 & 1,01 & $2,61^{* *}$ & 0,68 \\
91 & & 0,00 & 1,45 & 0,51 \\
92 & & & 0,00 & $2,39 * *$ \\
93 & & & & & 0,00 \\
\hline
\end{tabular}

*,**,***: Nível de significância de $0,1,1$ e $5 \%$.

Revista Brasileira de Finanças 1 (2) Dezembro 2003 


\subsubsection{Classes de Ações.}

A comparação entre classes de ações avaliou a influência da liquidez das ações no comportamento do preço das mesmas, uma vez que as ações preferenciais apresentam maior liquidez que as ordinárias. É de se presumir que as preferenciais devessem apresentar menores retornos anormais em função da maior liquidez.

Dos 686 eventos analisados, as ações ordinárias representaram 219 casos (32\%) enquanto que o restante (68\%) era composto por ações preferenciais. As ações ordinárias apresentam valores de $D P_{1 a}$ de $2,25 \%$ enquanto que as preferenciais de $2,59 \%$. Essa diferença não é significativa estatisticamente pois o teste $Z$ de diferença de médias apresentou um valor de igual a 0,60 e contraria a expectativa teórica.

Tabela 7 - Comparação entre Classes de Ações

\begin{tabular}{lcccc}
\hline \hline ON - PN & \multicolumn{2}{c}{$D P_{1 a}$} & \multicolumn{2}{c}{$D P_{2 a}$} \\
Estat. Descritiva & $\mathrm{ON}$ & $\mathrm{PN}$ & $\mathrm{ON}$ & $\mathrm{PN}$ \\
Média & $0,0225^{*}$ & $0,0259^{*}$ & $0,0116^{*}$ & $0,0162^{*}$ \\
Desvio Padrão & 0,0698 & 0,0691 & 0,0587 & 0,0628 \\
Mediana & 0,0123 & 0,0154 & 0,0061 & 0,0089 \\
Maior Valor & 0,3903 & 0,3206 & 0,2510 & 0,2872 \\
Menor Valor & $-0,1680$ & $-0,2991$ & $-0,1710$ & $-0,3049$ \\
Eventos & 219 & 467 & 219 & 467 \\
Teste T & 4,77 & 8,09 & 2,93 & 5,59 \\
Teste Z - ON/PN & 0,60 & & 0,94 & \\
\hline
\end{tabular}

*: Nível de significância de 0,1\%.

Foi analisada uma sub-amostra de 19 empresas que distribuíram dividendos para ações ordinárias e preferenciais ao mesmo tempo, com o objetivo de retirar um possível viés causado por empresas que pagaram dividendos para apenas uma 
classe de ação. Os resultados da Tabela 8 apresentam características semelhantes à amostra total, uma vez que os valores de $D P_{1 a}$ diminuíram de $2,25 \%$ para $1,32 \%$ nas ações ordinárias e de $2,59 \%$ para $0,86 \%$ no caso de preferenciais. O teste de diferença de médias não apresentou significância estatística.

Esses resultados estão em concordância com a expectativa teórica, uma vez que as ações preferenciais apresentaram diferença de preços menores que as ações ordinárias. Assim, ao contrário do teste anterior, é possível concluir que a liquidez das ações influencia a formação dos preços, já que as preferenciais, quando as empresas optam por pagar dividendos simultaneamente, apresentaram comportamentos inferior aos das ordinárias.

Tabela 8 - Comparação entre Classes de Ações - Empresas que Pagaram Dividendos para Ações ON e PN Simultaneamente

\begin{tabular}{lcccc}
\hline \hline ON - PN SIMULTÂNEO & \multicolumn{2}{c}{$D P_{1 a}$} & \multicolumn{2}{c}{$D P_{2 a}$} \\
Estat. Descritiva & $\mathrm{ON}$ & $\mathrm{PN}$ & $\mathrm{ON}$ & $\mathrm{PN}$ \\
Média & $0,0132^{* *}$ & $0,0086^{* * *}$ & $0,0072^{* * *}$ & 0,0030 \\
Desvio Padrão & 0,0552 & 0,0469 & 0,0511 & 0,0433 \\
Mediana & 0,0087 & 0,0057 & 0,0042 & 0,0033 \\
Maior Valor & 0,1727 & 0,1434 & 0,1593 & 0,1110 \\
Menor Valor & $-0,1680$ & $-0,1901$ & $-0,1710$ & $-0,1929$ \\
Eventos & 140 & 140 & 140 & 140 \\
Teste T & 2,82 & 2,18 & 1,66 & 0,82 \\
Teste Z - ON/PN & 0,74 & & 0,74 & \\
\hline
\end{tabular}

*,***: Nível de significância de 1 e $5 \%$ respectivamente.

\subsubsection{Setores da Economia.}

A comparação entre o setor das instituições financeiras e os outros setores visa identificar se o preço das ações dessas instituições comportavam-se de maneira diferente do resto da 
amostra. Este setor apresenta características particulares no que tange a risco e a regulações oriundas do Banco Central, constituem uma parcela significativa da amostra e apresentam uma freqüência de pagamento de dividendos significativamente superior aos setores restantes. Nesse caso, os dividendos podem ser considerados menos surpreendentes por serem mais previsíveis e, portanto, os resultados dos eventos do setor financeiro deveriam ser menores que os demais setores.

Como esperado, o resultado de $D P_{1 a}$ para o setor financeiro foi de 1,48\% enquanto que o restante da amostra apresentou $3,27 \%$. Essa diferença apresentou significância de 0,1\% com um valor do teste $Z$ igual a 3,42 e reforça a expectativa teórica.

Tabela 9 - Comparação entre Setores

\begin{tabular}{lccc}
\hline \hline$D P_{1 a}$ & Inst. Financeiras & Outros & Teste Z \\
Média & $0,0148^{*}$ & $0,0327^{*}$ & $3,42^{*}$ \\
Desvio Padrão & 0,0642 & 0,0722 & \\
Mediana & 0,0062 & 0,0213 & \\
Maior Valor & 0,3903 & 0,3206 & \\
Menor Valor & $-0,2991$ & $-0,1372$ & \\
Eventos & 303 & 383 & \\
Teste T & 4,02 & 8,85 & \\
\hline & & & \\
& & & \\
\hline$D P_{2 a}$ & Inst. Financeiras & Outros & \\
Média & $0,0060^{* * *}$ & $0,0217^{*}$ \\
Desvio Padrão & 0,0563 & 0,0646 & \\
Mediana & 0,0019 & 0,0129 & \\
Maior Valor & 0,2510 & 0,2872 & \\
Menor Valor & $-0,3049$ & $-0,1523$ & 383 \\
Eventos & 303 & 6,57 & \\
Teste T & 1,85 & respectivamente. &
\end{tabular}




\subsubsection{Yields das Ações.}

A comparação da amostra entre yields buscou identificar uma relação entre yield e o excesso no preço de $P_{1}$ encontrado nos testes anteriores. Nesse caso a amostra é segmentada em decis com o objetivo de testar se há uma relação linear entre os mesmos. Também é possível comparar os decis extremos para verificar se são significativamente diferentes.

Analisando os resultados encontrados, o $1^{\underline{\mathrm{O}}}$ decil apresentou um valor de $D P_{1 a}$ de $0,28 \%$ enquanto que no $10^{\underline{O}}$ decil obteve-se $11,85 \%$. O teste de diferença de médias apontou um valor para $Z$ igual a 8,87 e significativo a $0,1 \%$. Essas constatações contrariam as expectativas teóricas e o crescimento do yield foi refletido por um incremento proporcional na diferença de preço da ação na data "1". A correlação entre o yield e o valor de $D P_{1 a}$ foi de 0,97 , evidenciando a existência de uma muito forte correlação entre os mesmos.

\section{Tabela 10 - Diferença de Médias - Yield}

\begin{tabular}{lccc}
\hline \hline$D P_{1 a}$ & $1^{\underline{O}}$ Decil & $10^{\underline{O}}$ Decil & Teste Z \\
Média & 0,0028 & 0,1185 & $8,87^{*}$ \\
Desvio Padrão & 0,0317 & 0,1029 & \\
Mediana & 0,0028 & 0,1097 & \\
Maior Valor & 0,0863 & 0,3903 & \\
Menor Valor & $-0,0727$ & $-0,1378$ & \\
Eventos & 69 & 68 & \\
Teste T & 0,72 & $9,49^{*}$ & \\
Yield (médio) & 0,0007 & 0,1139 & \\
\hline DP $P_{2 a}$ & & & \\
Média & $1^{\underline{O}}$ Decil & $10^{\underline{O}}$ Decil & Teste Z \\
Desvio Padrão & 0,0025 & 0,0689 & \\
Mediana & 0,0317 & 0,0943 & \\
Maior Valor & 0,0027 & 0,0661 & \\
Menor Valor & 0,0860 & 0,2682 & \\
Eventos & $-0,0731$ & $-0,1759$ & \\
Teste T & 69 & 68 & \\
\hline
\end{tabular}

*: Nível de significância de $0,1 \%$. 


\subsection{Manutenção dos Preços após a Data "0".}

Após a realização dos testes acima aplicados ao modelo de Elton e Gruber, é importante verificar se os resultados encontrados não são fruto de alguma especulação momentânea que algum agente do mercado tenha descoberto ou de uma sobrereação como conseqüência do pagamento em si dos dividendos como forma de redução do risco previsto pelo mercado, ou seja, uma nítida preferência pelo "bird-in-hands" (Battacharya, (1979)). A verificação dos níveis de preço das ações em uma janela de evento se faz necessária. O cálculo dos retornos anormais foi realizado para cada dia da janela do evento com base no modelo de retorno ajustado ao mercado (procedimento 2.2).

Da amostra total de 693 eventos, constatou-se um retorno anormal médio positivo de $1,4 \%$ na data " 1 " com significância de $0,1 \%$ (Tabela 11). Retirando-se os outliers, obteve-se uma sub-amostra com 464 eventos que apresentou um retorno anormal positivo na data " 1 " de $0,68 \%$ (Tabela 12), ainda significativo a $0,1 \%$.

A Figura 1 apresenta o comportamento dos retornos anormais acumulados para a amostra total e após a exclusão dos outliers. Uma constatação importante é que os preços das ações tenderam a retornar para o valor dos último dia de negociação com direito a dividendos. Então constata-se que houve um pico no preço da ação em torno da data ex-dividend evidenciando uma anormalidade do mercado brasileiro. 
Figura 1 - Valores de CAR para a Amostra total e Amostra sem Outliers

\section{Considerações Finais.}

Este estudo testou a existência do efeito clientela no cenário brasileiro, verificando se o preço das ações que pagaram dividendos durante os anos de 1989 a 1993 comportou-se conforme o previsto por ELTON e GRUBER (1970). Também verificou a existência de alguma anormalidade no retorno das ações na data ex-dividend, estendendo esta análise para um período de -5 a +5 dias em relação à última data em que a ação era negociada com direito a receber dividendos.

Dos 693 eventos analisados, em apenas cinco por cento dos casos, o valor da ação no $1^{\mathrm{O}}$ dia após o pagamento do dividendo situou-se dentro do intervalo teórico esperado, e 47\% dos eventos apresentaram um resultado surpreendente, em que o preço da ação no primeiro dia ex-dividend foi maior do que na data em que a ação tinha direito de receber dividendos. 
Utilizando a amostra total ajustada ao mercado, encontrou-se uma diferença média no preço da ação $\left(D P_{1 a}\right)$ no primeiro dia ex-dividend de 3,23\% superior ao valor mínimo esperado para o modelo teórico, e uma diferença de $2,48 \%$ após a exclusão dos outliers, em ambos os casos com níveis de significância de 0,1\%. Essas constatações contrariam fortemente as expectativas do modelo, uma vez que esse comportamento pode ser considerado irracional por parte dos investidores, já que estariam pagando, por uma ação sem direito a dividendos, um valor maior do que foi pago quando a ação tinha direito a recebê-los.

Quando a amostra é segmentada por ano (de 1989 a 1993) encontramos uma diferença positiva de preço em torno de $2,5 \%$ (exceto no ano de 1992), sendo este um resultado contrário às nossas previsões.

Quando segmentada por classe de ações, e liquidez de uma forma indireta, os resultados confirmaram as expectativas teóricas pois as mais líquidas apresentaram diferenças de preços menores.

As instituições financeiras responderam com diferenças de preços muito menores que os demais setores.

$\mathrm{Na}$ diferenciação por yields, as ações pagadores de maiores yields tiveram, contra as expectativas teóricas, suas diferenças de preços maiores.

Verificando o comportamento do preço das ações após o pagamento dos dividendos encontramos um pico no retorno anormal das ações em torno da data ex-dividend de 1,4\% (0,68\% para a amostra sem outliers) retornando ao valor inicial após 5 dias do evento. Isto demonstra que a sobre-reação existente é pontual.

Os resultados contrariaram os modelos teóricos e podem ser considerados surpreendentes se comparados aos resultados obtidos em estudos sobre esse assunto realizados anteriormente no 
mercado brasileiro e em outros países, uma vez que evidenciase uma imperfeição no ajuste de preços das ações nas datas ex-dividend. Além disso, a segmentação por yield contraria a existência de efeito clientela no mercado acionário brasileiro.

Submetido em Agosto de 2003. Revisado em Outubro de 2003.

\section{Referências}

Allen, F. \& Michaely, R. 2002. "Payout Policy". NorthHolland Handbook of Economics edited by George Constantinides, Milton Harris, and Rene Stulz; North-Holland.

Amihud, Y. \& Murgia, M. 1997. "Dividends, Taxes, and Signaling: Evidence from Germany". Journal of Finance, vol. LII, 1,397-408.

Battacharia, S. 1979. "Imperfect Information, Dividend Policy, and The Bird in Hand Fallacy". Bell Journal of Economics, 10(1), 259-270.

Black, F. 1976. "The Dividend Puzzle". Journal of Portifolio Management, 5-8.

Brasil. Lei 6.404, de 15 de dezembro de 1976.

- Lei 8.981, de 20 de janeiro de 1995.

Brown, S. \& Warner, J. 1980. "Measuring Security Price Performance". Journal of Financial Economics, 8,3, 205-58.

1985. "Using Daily Stocks Returns: The Case of Event Studies". Journal of Financial Economics, 14, 4, 03-31.

Donaldson, G. 1961. Corporate Debt Capacity: A Study of Corporate Debt Policy and the Determination of Corporate Debt Capacity. Harvard Graduate School of Business.

Easterbrook, Frank H. 1984. "Two Agency-cost Explanations of Dividends". American Economic Review, 221-230. 
Elton, E. J. \& Gruber, M. J. 1970. "Marginal Stockholders Tax Rates and the Clientele Effect". Review of Economics and Statistics, 68-74.

Frank, M., Jagannathan, R. 1998. "Why do Stock Prices Drop by Less than the Value of the Dividend? Evidence from a Country Without Taxes". Journal of Financial Economics, 47, 161-188.

Hayashi, F. \& Jagannathan, R. 1990. "Ex-Day Behavior of Japanese Stock Prices: New Insights from New Methodology". Journal of the Japanese and International Economies, 4, 401-427

Jensen, M. C. 1986. "Agency Cost of Free Cash Flow, Corporate Finance, and Takeovers". American Economic Review, 76(2), 323-329.

Kalay, A. 1982. "The Ex-Dividend Behavior of Stock Prices: A Re-examination of The Clientele Effect". Journal of Finance, 37, 1059-1070.

Kato, K., Loewenstein, U. 1995. "The Ex-Dividend Behavior of Stock Prices: The Case of Japan". Review of Financial Studies, 8: 617-647.

Kloeckner, G. O. 1995. "Estudos de Eventos: A Análise de um Método". Revista Brasileira de Administração Contemporânea, 01, 02, 261-270.

Lasfer, M. \& Zenomos, M. 2003. "The Tax Impact on the ExDividend Dates: Evidence from European Firms", Working Paper.

Mackinlay, C. 1997. "Event Studies in Economics and Finance". Journal of Economic Literature, 35, 13-39.

Michaely, R. \& Murgia, M. 1995. "The Effect of Tax Heterogeneity on Prices and Volume Around the Ex-dividend Day: Evidence from the Milan Stock Exchange". The Re- 
view of Financial Studies, 8, 369-399.

Miller, M. \& Modigliani, F. 1961. "Dividend Policy, Growth, and the Valuation of Shares". Journal of Business, 411433.

Miller, M. \& Scholes, M. 1978. "Dividends and Taxes". Journal of Financial Economics, 6, 333-64.

Milonas, N. \& Travlos, N. 2001. "The Ex-dividend Day Stock Price Behaviour in the Athenas Stock Exchange", Working Paper.

Neto, J. \& Saito, R. 2003. "Pagamentos de Dividendos e Persistência de Retornos Anormais das Ações: Evidência do Mercado Brasileiro". RAUSP, 38(2).

Procianoy, J. L. \& Verdi, R. 2003. "Dividends clientele, new insights and new questions: The Brazilian case". Working Paper.

Ramos, C. 1997. "A Influência da Tributação Sobre o Retorno das Ações em Função da Distribuição de Dividendos feita pelas Companhias Negociadas na Bovespa: um Estudo do Mercado Brasileiro". Dissertação de mestrado, PPGA/UFRGS.

Romon, F. 2000. "Contribution of Dividend Policy Stability to the Measurement of Dividend Annoucement and Exdividend Effects on the French Market". Working Paper.

Ross, S., Westerfield, Randolph \& Jaffe, Jeffrey 1999. Corporate Finance, fifth edition, McGraw-Hill.

Verdi, R. 2001. "A influência dos impostos sobre o pagamento de dividendos no preço das ações: um estudo do mercado brasileiro". Dissertação de mestrado, PPGA/UFRGS. 